\title{
Circadian rhythm and cardiovascular disorders
}

\author{
This article was published in the following Dove Press journal: \\ ChronoPhysiology and Therapy \\ 8 July 2014 \\ Number of times this article has been viewed
}

Lilei Zhang ${ }^{1-3}$

Mohamed Khaled Sabeh ${ }^{2,3}$

Mukesh K Jain ${ }^{2,3}$

'Department of Genetics and Genome Sciences, ${ }^{2}$ Case Cardiovascular

Research Institute, Case Western Reserve University, ${ }^{3}$ Harrington Heart and Vascular Institute, Department of Medicine, University Hospitals at Case Medical Center, Cleveland, OH, USA

Correspondence: Mukesh K Jain Case Cardiovascular Research Institute, 2103 Cornell Road, Room 4-522, Cleveland, OH 44I06, USA

$\mathrm{Tel}+\mathrm{I} 2163683607$

Fax + I 2163680556

Email mukesh.jain2@case.edu
Abstract: Circadian rhythmicity affects all living organisms on earth. Central and peripheral cellular clocks have the ability to oscillate and be entrained to environmental cues, thus allowing organisms to anticipate and synchronize their physiologic processes and behavior to recurring daily environmental alterations. Disruption of the circadian rhythm in modern life, such as by shift work and jet travel, leads to dyssynchrony of the central and peripheral clocks, and is an independent risk factor for cardiovascular disease and the metabolic syndrome. Aging has also been associated with attenuated cellular rhythmicity. Here we summarize the clinical observations linking cardiovascular health to circadian rhythm. In addition, we discuss recent advances in experimental models for understanding the clock machinery in terms of a variety of physiologic processes within the cardiovascular system. Together, these studies build the foundation for applying our knowledge of circadian biology to the development of novel therapy for cardiovascular disorders.

Keywords: circadian rhythm, diurnal variation, cardiovascular

\section{Introduction}

Cardiovascular disease is the leading cause of morbidity and mortality in the USA, affecting more than one in three US adults and resulting in enormous health care expenditure, which was $\$ 444$ billion in $2010 .{ }^{1}$ Given the huge impact of cardiovascular disease, intensive effort is being made to understand the basic mechanisms governing cardiovascular function in health and disease. One area of investigation that has gained momentum in recent years is the influence of circadian rhythms on cardiovascular biology.

Circadian (from the Latin, circa diem, meaning "approximately daily") rhythm refers to any biological process that exhibits a 24-hour periodicity. Physiologic parameters of the cardiovascular system, such as heart rate, blood pressure (BP), vascular tone, and QT interval, show significant diurnal variation. ${ }^{2-4}$ Pathologic states, such as arrhythmogenic sudden cardiac death (SCD), myocardial infarction (MI), aneurysmal rupture, and stroke, also show a daily rhythmic pattern, with peak susceptibility in the early morning hours..$^{5-8}$ In addition, disruption of the circadian rhythm either in the brain (central clock) or in the peripheral tissues (peripheral clock) leads to cardiovascular disease in both human and animal models. ${ }^{9-19}$ In this review, we summarize our current understanding of the interplay between circadian regulation and cardiovascular disease, as well as future directions in development of therapy. 
Clinical observations linking circadian and cardiovascular biology Blood pressure

$\mathrm{BP}$ is known to show diurnal variation, with a peak in the mid-morning and a trough at night, with a $10 \%$ variation in ambulating humans. ${ }^{2}$ Diurnal BP variation results primarily from cyclic physical activity, including sleep-awake cycles, as demonstrated by studies in shift workers. ${ }^{20}$ Endogenous factors, although influenced by activity, contribute to the diurnal variation of BP via circadian variation in the autonomic nervous system, arterial vascular tone, and humoral factors, including the renin angiotensin aldosterone axis, catecholamines, and cortisol. The heritability of circadian $\mathrm{BP}$ and heart rate variation may reflect the heritability of these endogenous factors. ${ }^{21}$

The association between this diurnal variation and predisposition to disease has been noted in both normotensive and hypertensive individuals. O'Brien et al were the first to observe the increased risk of stroke in nondippers. ${ }^{22}$ Subsequent studies classified subjects into four groups according to their diurnal/nocturnal BP ratio $(100 \times($ mean diurnal BP - mean nocturnal BP)/mean diurnal BP): nondippers (ratio $<10 \%$ ), dippers (ratio 10\%-20\%), extreme dippers (ratio $>20 \%$ ), and inverse dippers or risers (ratio $<0 \%$, as mean nocturnal $\mathrm{BP}$ is higher than mean diurnal BP). Nondipping was associated with secondary hypertension and ${ }^{23,24}$ endothelial dysfunction, ${ }^{23,25}$ as well as a higher risk for cardiovascular events and adverse outcomes, including heart failure and $\mathrm{MI},{ }^{26,27}$ stroke, left ventricular hypertrophy, ${ }^{28}$ deterioration of kidney function, ${ }^{29,30}$ and progression to end-stage renal disease. ${ }^{31}$ Further, nondipping hypertensive individuals were shown to have a three-fold increase in adverse cardiovascular events than dipping hypertensives. ${ }^{32}$ The Ohasama study of 1,542 Japanese people revealed a linear relationship between the nocturnal decline in BP and cardiovascular mortality. Each 5\% decrease in the decline (nondipping) was associated with an approximately $20 \%$ increase in the risk for cardiovascular mortality. ${ }^{33}$ The group with riser BP had the highest risk for both fatal and nonfatal stroke when compared with the other three groups. ${ }^{34}$ Several mechanisms have been proposed to explain the higher night-time BP and associated worse outcome, ie, nocturnal autonomic dysfunction, disturbed baroreflex sensitivity, sleep apnea, abnormal sodium handling, and nocturnal volume overload.

The role of the morning surge in BP, however, is more controversial. A steeper surge of morning BP has been associated with an increase in intima media thickness, ${ }^{35}$ increased inflammatory markers (such as a higher number of macrophages and T-lymphocytes, as well as more ubiquitinproteasome, tumor necrosis factor- $\alpha$, and nuclear factorkappa B activity), ${ }^{36}$ and higher stroke rates.${ }^{37}$ The largest study of relevance so far was reported by $\mathrm{Li}$ et al, who analyzed 5,645 individuals over a median follow-up of 11.4 years and concluded that people in the top $10 \%$ of the morning systolic surge are associated with increased all-cause mortality as well as adverse cardiovascular events. ${ }^{38}$ However, given that the morning surge is defined as the difference between the lowest night-time BP or preawakening BP and the first morning BP, it is not surprising that a blunted "dipping" and a blunted morning surge (overall flat) may be closely linked. Indeed, Verdecchia and Hermida observed that a blunted morning surge was associated with an increased risk for cardiovascular events, but did not find an effect on total mortality. ${ }^{39}$ More standardized definition and measurement is critical to reconcile these seemingly discrepant findings.

\section{Arrhythmia/sudden cardiac death}

Electrocardiographic measurements, such as P-wave duration and area, P-R interval, QRS duration, and corrected QT (QTc) interval all show circadian variation in healthy individuals. ${ }^{3,4}$ Both atrial and ventricular tachyarrhythmias show a circadian clustering, with a peak in the early morning hours, as reviewed previously by Portaluppi et al. ${ }^{40}$ The only exception seems to be vagally mediated atrial fibrillation, which tends to occur at night, with a second peak after lunch when vagal drive dominates.

The majority of SCDs are thought to result from coronary artery disease, whether fatal ventricular arrhythmia due to an acute plaque rupture or chronic ischemic cardiomyopathy. ${ }^{41}$ Implantable cardiac defibrillators allow faithful extended recording of ventricular arrhythmias in the outpatient setting and have greatly improved our understanding of the circadian rhythmicity of cardiac arrhythmia and SCD. The primary early morning peak and secondary late afternoon peak has been confirmed by a number of investigators, including in a meta-analysis by Cohen et al, who reported a morning excess in the incidence of SCD based on analysis of 19,390 patients, with $30 \%$ of SCD occurring between 6 am and noon (relative risk 1.29, 95\% confidence interval 1.26-1.32)..$^{5}$ The early morning excess of SCD is also independent of whether ischemic heart disease is present, ${ }^{42-44}$ suggesting mechanisms other than ischemia, eg, other endogenous circadian factors, such as metabolites, and intrinsic susceptibility of the myocardium.

Another interesting observation is patients with obstructive sleep apnea, who seem to have a marked nocturnal peak 
for SCD, have the highest incidence between midnight and 6 am (relative risk 2.57, 95\% confidence interval 1.87-3.52). ${ }^{45}$ Obstructive sleep apnea is associated with increased nocturnal sympathetic tone, BP, autonomic dysfunction, and platelet aggregation, all of which increase the risk for adverse cardiac events. In addition, hypoxia can lead directly to cardiac ischemia and arrhythmia. Oxygenation can improve the electrical stability of the myocardium in animal models and alleviate arrhythmia in humans. ${ }^{46,47}$ However, it is not known if the standard of care, ie, the nocturnal continuous positive airway pressure device, can restore normal sleep physiology and circadian rhythm in these individuals.

Patients with long QT (LQT) syndrome provide a unique opportunity to study the biology of the time-of-day dependency of arrhythmia. Stramba-Badiale et al were the first to demonstrate that QT prolongation at night is genotypedependent, with only LQT3 patients showing significant lengthening of QTc at night, which is consistent with the clinical observation that night-time events are most frequent in LQT3 patients with mutations in $S C N 5 A .{ }^{48}$ This was the first suggestion that the intrinsic circadian rhythm of a singular channel might contribute to the diurnal distribution of arrhythmic events.

\section{Myocardial infarction}

In 1985, Muller et al were the first to confirm the long suspected early morning clustering of MI, using creatine kinase to estimate the time of occlusion. ${ }^{6}$ This finding was confirmed in subsequent studies, including a meta-analysis of 60,000 patients by Cohen et $\mathrm{al}^{7}$ and a study of 45,218 patients from the National Cardiovascular Data Registry reported by Mogabgab et al. ${ }^{49}$ Similar findings have been reported for unstable angina, stent thrombosis, and transient myocardial ischemia. ${ }^{50,51}$ This circadian effect is abolished by a $\beta$-blocking agent or aspirin, suggesting involvement of both adrenergic activity and platelet aggregation. ${ }^{6,52}$

Despite the agreement regarding time of onset, circadian variation in the size of MI remains a focus of study and debate. Multiple groups have attempted to answer this challenging question in humans. Two retrospective studies and one prospective study have independently demonstrated that a larger infarct size, estimated by biomarker release, in patients with ST-elevation MI undergoing primary percutaneous coronary intervention is associated with onset of symptoms in the sleep-wake transition. ${ }^{53-55}$ However, a recent prospective multicenter, multiethnic cohort study did not find a clear circadian dependence of infarct size either in the entire data set or in each of the three participating countries separately. ${ }^{56}$
Unlike symptoms of ischemia, infarct size is influenced not only by the circadian biology of the patient, but also by the circadian biology of their health care providers, who are shift workers themselves and under different levels of stress in a time-of- day-dependent manner. This added complexity must be taken into consideration and may require larger cohorts and better designed controls, both of which are extremely challenging in human studies.

\section{Stroke/thromboembolism/ pulmonary embolism}

It has long been recognized that, like MI, arrhythmia, and $\mathrm{SCD}$, ischemic cerebrovascular events have a peak incidence in the early morning with a secondary peak in the afternoon. A large multicenter observational study reported the most frequent time of onset of stroke to be between 8 am and $11 \mathrm{am}^{7}$ This observation suggests a common mechanism that likely involves circadian rhythmicity of hemodynamic (BP, vascular tone, autonomic function), hemostatic (platelet aggregation), and fibrinolytic (thrombogenic versus thrombolytic) factors. Interestingly, although occurring via a different mechanism, hemorrhagic cerebrovascular events also follow the same trend, according to multiple studies. ${ }^{57-61}$ Increased sympathetic tone and an arterial BP surge in the morning have been considered to be relevant driving forces.

\section{Aneurysm rupture/dissection}

Abdominal and thoracic aortic dissection and aneurysm rupture have been observed to have a time-of-day-dependent incidence, with a peak in the 6 am to noon window. It was first reported in two retrospective Italian studies ${ }^{62,63}$ of acute rupture of thoracic aortic aneurysm and abdominal aortic aneurysm, respectively, which identified a primary peak at 10 am and a secondary peak at $8 \mathrm{pm}$. Subsequent studies worldwide have come to the same conclusion; ${ }^{8,64-67}$ in particular, a large study by Mehta et $\mathrm{al}^{8}$ evaluated 957 patients enrolled in the International Registry of Acute Aortic Dissection (IRAD) between 1996 and 2000 and found a significantly higher frequency of acute aortic dissection between 6 am and noon in the entire data set as well as in an analysis of subgroups according to age, sex, type of dissection, and BP. This interesting observation suggests that the underlying mechanism is independent of these factors, including BP, which was thought to be the driving factor for the diurnal variation of adverse cardiovascular events. The only subgroup that did not show a significant circadian variation was patients with diabetes, and this has been observed similarly in MI. 


\section{Diabetes/autonomic dysfunction}

Diabetic patients are at very high risk for adverse cardiovascular events, but fail to show normal circadian fluctuations in the occurrence of $\mathrm{MI}^{68-70}$ or acute aortic dissection. ${ }^{8}$ The reduction in diurnal heart rate and variation in QT interval associated with increased autonomic dysfunction in patients with diabetes has been known for 30 years. ${ }^{71,72}$ Blunted nocturnal BP "dipping" is also prevalent in diabetic patients. ${ }^{73-75}$ Disruption of circadian rhythm may explain the change in peak incidence of cardiovascular events in these patients. In addition, loss of normal circadian rhythm may result in a continuous vulnerability to adverse events and explain the excess disease burden in these patients.

\section{Shift work}

Shift work is common in many occupations, including the health care professions. Recent epidemiologic studies in the US and in Europe show that 15\%-20\% of employees are shift workers. Shift work leads to dyssynchronization of the central (brain) and peripheral clocks (eg, liver and heart; please refer to the next section for a detailed discussion on these). It has also been associated with behavioral risk factors, including smoking and poor dietary habits. Further, increased stress leads to neurohormonal changes that may adversely affect BP, lipid profile, and systemic metabolism. It has long been known that there is an increased risk of coronary artery disease amongst shift workers, and more recently diabetes and metabolic syndrome, which are direct risk factors for coronary artery disease. ${ }^{9,10,76,77}$ Other risk factors such as hypertension and dyslipidemia have also been associated with shift work. Knutsson et al reported a significantly increased risk of ischemic heart disease in 504 paper mill shift workers when compared with day workers and a dose response to the duration of shift work (relative risk 2.2 for 11-15 years; relative risk 2.8 for $16-20$ years). It was generally acknowledged, including in several meta-analyses, that shift work increases the risk of cardiovascular disease by about 40\%. ${ }^{9,78,79}$ However, more recent studies have shown mixed results, including a meta-analysis by Frost et al which did not find an increased risk for ischemic heart disease in shift workers. ${ }^{80}$ Overall, most studies point in the direction of an adverse effect of shift work.

\section{Molecular clock mechanism, the central clock, and the peripheral clock}

The molecular circadian clock mechanism, which synchronizes changes in gene expression with recurring patterns of daily life, such as eating and sleeping, is identified in all tissues and cell types. In mammals, the central clock exists in the suprachiasmatic nucleus in the hypothalamus, and peripheral clocks exist in all other tissues and cell types. The core molecular clock is composed of a transcriptional/translational feedback loop that synchronizes rhythmic gene expression downstream (reviewed by Takahashi et al) ${ }^{81}$ CLOCK and BMAL1 constitute the positive limb and drive transcription of Period (PER) and Cryptochrome (CRY) in the negative limb. Once PER and CRY reach a threshold level, they enter the nucleus and inhibit the CLOCK:BMAL1 heterodimer on their own promoters. The nuclear hormone receptors, REV-ERB $\alpha$ and $\beta$ and RAR-related orphan receptor $\alpha$ (ROR- $\alpha$ ), are both transcription targets of the CLOCK:BMAL1 complex and represses and activates BMAL1 transcription, respectively, to facilitate the robustness and stability of the clock. In addition, casein kinase I $\varepsilon$ and $\delta(\mathrm{CsK})$ also contribute to the regulation of clock proteins.

Recent landmark research by O'Neill et al demonstrated biochemical oscillations in the oxidation-reduction state of peroxiredoxin, an antioxidant protein, as a conserved timekeeping mechanism in all three kingdoms of life..$^{82}$ The oxidation-reduction cycle of peroxiredoxin is completely independent of transcription, as was observed in human mature red blood cells, which are anucleated as well as Ostreococcus tauri in the darkness, under which condition, transcription is completely shut off. ${ }^{83,84}$ This work turned an exciting new page in the field of circadian rhythm and cellular reduction-oxidation state.

The central clock controls the entrainment of various biological activities to zeitgebers (from the German meaning "time givers"), mainly light. The central clock receives photic input from the retina, projects to different regions of the brain, and secretes circulating factors to mediate physiologic rhythms both within the brain and in the periphery, thus coordinating the physiology and behavior of the organism. ${ }^{81}$ Lesions of the suprachiasmatic nucleus in rats abolish the circadian pattern of BP and heart rate without affecting minute-to-minute variation, thus providing evidence in support of central regulation of BP and heart rate through the clock in the suprachiasmatic nucleus. However, food intake also became arrhythmic, which suggested that activity is similarly affected. ${ }^{11}$ The critical role of the central clock in the cardiovascular system is highlighted further by the aforementioned increased risk of cardiovascular events and the metabolic syndrome in shift workers.

The peripheral clock allows the multicellular organism to anticipate environmental changes, coordinate metabolic 
processes, and maximize energy efficiency. The zeitgebers for the peripheral clocks are less clear, because they are not only coupled to the central clock but are also able to oscillate autonomously. Indeed, environmental cues, such as restricted feeding, were found to be able to override the central clock locally and cause dyssynchrony between the central and peripheral clocks, as seen in the shift work paradigm. ${ }^{85}$ In the cardiovascular system, it is believed that neurohumoral factors play important roles in synchronizing the central and peripheral clocks, although the detailed mechanisms are as yet not well understood. High throughput studies confirm that approximately $10 \%$ of transcripts in each peripheral tissue type oscillate in a circadian fashion under the control of core clock genes; however, there is little overlap between the different tissues, and the total number of oscillating genes is estimated to be close to $50 \%$ of the transcriptome ${ }^{86-88}$ The role of the peripheral clock in the cardiovascular system is becoming a fast emerging field, and is elucidated further in the next section.

\section{Mechanistic basis for circadian control of cardiovascular biology}

Animal models of genetically engineered mutant core clock machinery have been instrumental in isolating and identifying the role of the clock component in the cardiovascular system. This section discusses the experimental evidence for circadian regulation of the intrinsic components (cardiac and vascular) of the cardiovascular system as well as extrinsic factors (neurohumoral and hematological) that act directly on the cardiovascular system and affect its function.

\section{Intrinsic factors}

\section{Cardiac}

The peripheral clock in cardiomyocytes has been shown to affect all major processes of the myocardium, from energy metabolism to contractile function and from response to injury to electrophysiologic properties.

\section{Energy metabolism}

The peripheral clock regulates many aspects of myocardial metabolism and allows the heart to anticipate and adapt to different sources of energy and demand efficiently in a timeof-day-dependent manner. Chatham and Young recently reviewed this topic in detail. Briefly, the clock machinery regulates myocardial glucose uptake, flux via the glycolysis and hexosamine biosynthetic pathway, and pyruvate oxidation, as well as glycogen, triglyceride, and protein turnover ${ }^{89}$ For example, the homozygous Clock mutant mouse model mimics the metabolic syndrome of hyperleptinemia, hyperlipidemia, hepatic steatosis, hyperglycemia, and hypoinsulinemia. ${ }^{90}$ Cardiomyocyte-specific Clock mutant (CCM, dominant negative) mice show attenuated induction of myocardial fatty acidresponsive genes during fasting. ${ }^{91}$ Moreover, in CCM hearts, myocardial oxygen consumption and fatty acid oxidation rates were increased and cardiac efficiency was decreased, without alterations in mitochondrial content or structure and only modest mitochondrial dysfunction. ${ }^{14}$

\section{Contractile}

Basal contraction and intracellular calcium levels were significantly greater in rat cardiomyocytes isolated during resting periods versus active periods. The increase in systolic intracellular calcium in response to isoproterenol was also significantly greater in resting periods than in active periods, reflecting a greater calcium load in the sarcoplasmic reticulum in the resting period. ${ }^{92}$ Wild-type hearts but not CCM hearts showed a marked diurnal variation in responsiveness to an elevation in workload ex vivo, with a greater increase in cardiac power and efficiency during the dark (active) phase than in the light (inactive) phase. ${ }^{93}$

Qi and Boateng put forward an interesting hypothesis that CLOCK localizes to the sarcomeric z-disk and senses myofilament cross-bridge activity in neonatal cardiomyocytes. ${ }^{94}$ However, this has been challenged recently by Wang et al because of a lack of specificity of the key antibody used in the first study. ${ }^{95}$ In addition, Lefta et al showed subtle shifts in titin isoform composition, altered myosin heavy chain gene expression at the mRNA level, and disruption of sarcomere structure in BMAL1 null hearts, although passive tension in single cardiomyocytes was unaltered. ${ }^{96}$ These studies suggest a possible role for the molecular clock in regulating the passive properties and structure of sarcomeres in addition to their active contractile properties, but more definitive studies are needed.

\section{Hypertrophy}

Wild-type mice were found to show a five-fold increase in cardiac hypertrophy when challenged with the hypertrophic agonist isoproterenol at the active-to-sleep phase transition compared with administration of isoproterenol at the sleepto-active phase transition. This diurnal variation was not seen in CCM mice, which showed exaggerated hypertrophy at baseline. ${ }^{14}$ Global BMAL1-deficient mice develop dilated cardiomyopathy with advancing age, and cardiomyocytespecific knockout mice show increased biventricular weight and Mcip1 expression. ${ }^{14,96}$ Further, Martino et al have demonstrated that pressure overload (transverse aortic constriction) 
in mice maintained in a disruptive 20-hour rhythm versus a normal 24-hour rhythm environment leads to worsened dilated cardiomyopathy. ${ }^{97}$ Most interestingly, captopril, an angiotensin-converting enzyme inhibitor, benefited cardiovascular remodeling with improved cardiac function only when administered during sleep; wake-time captopril has an identical effect on cardiac remodeling and function to that of placebo, although achieved the same BP control as sleep time administration. ${ }^{98}$

\section{Ischemia/reperfusion}

In a rat coronary ischemia/reperfusion model, the amplitude of circadian clock gene oscillation, measured by messenger RNA level, was rapidly attenuated in the ischemia/reperfusion region when compared with the nonischemic region. This attenuation was not observed with hypoxia induced by a hypobaric chamber, suggesting that the clock machinery is involved in the response to ischemia/reperfusion, independent of hypoxia. ${ }^{99}$ Durgan et al showed that wild-type mouse hearts subjected to ischemia/reperfusion at the sleep-to-wake transition (ZT12) had a 3.5-fold increase in infarct size compared with hearts subjected to ischemia/ reperfusion at the wake-to-sleep transition (ZT0) and this variation was abolished in CCM mice. This study provides the first evidence that there is a time-of-day-dependent susceptibility to ischemia/reperfusion that is intrinsic to cardiomyocytes. ${ }^{13}$ Studies by Virag et al showed that mPer 2 mutant (functional null) mice have reduced infarct by $43 \%$ after nonreperfused MI, by $69 \%$ after ischemia/ reperfusion, and by $75 \%$ after preconditioned ischemia/ reperfusion, respectively. ${ }^{15,16}$ However, Eckle et al found that mPer 2 mutant mice had larger infarct sizes and loss of the cardioprotection conferred by ischemic preconditioning when compared with wild-type mice. ${ }^{100}$ The same group also found a reduction in infarct size at ZT12 and ZT18 compared with ZT0, which is different from the first report by Durgan et al. ${ }^{13}$ Although different surgical techniques and protocols (time-of-day) were used and may have contributed to the different results, more studies are needed to elucidate the reasons for this discrepancy.

Adenosine signaling has been implicated in the cardiac adaptation to limited availability of oxygen. Eckle et al identified PER2 as a target of adenosine receptor A2b, signaling of which leads to stabilization of PER2 during myocardial ischemia and subsequent stabilization of hypoxia-inducible factor- $1 \alpha$ and induction of glycolysis. Most interestingly, stabilization of PER2 in the heart achieved by exposing mice to intense light resulted in transcriptional induction of glycolytic enzymes and PER2-dependent cardioprotection from ischemia. ${ }^{100}$

\section{Excitability}

Our group provided the first molecular evidence of circadian transcriptional regulation of channel activity as a mechanism for cardiac arrhythmogenesis. Specifically, we reported that cardiac ion channel expression and QT interval duration (an index of myocardial repolarization) show endogenous circadian rhythmicity under the control of a clock-dependent oscillator, Krüppel-like factor 15 (KLF15). KLF15 transcriptionally controls the rhythmic expression of $\mathrm{Kv}$ channel-interacting protein 2 , a critical subunit required for generating the transient outward potassium current. Both a deficiency and an excess of KLF15 cause loss of rhythmic QT variation, abnormal repolarization, and enhanced susceptibility to ventricular arrhythmias. ${ }^{101}$ Schroder et al subsequently demonstrated that cardiomyocyte-specific Bmall knockout (iCS $\Delta$ Bmal1-/-) mice had a slowed heart rate, prolonged R-R and QRS intervals, and increased episodes of arrhythmia. Isolated $\mathrm{iCS} \Delta \mathrm{Bmal1-/-} \mathrm{hearts} \mathrm{were} \mathrm{more} \mathrm{sus-}$ ceptible to arrhythmia during electromechanical stimulation. Further, the same group identified Scn $5 a$, which encodes the principal cardiac voltage-gated sodium $(+)$ channel $(\mathrm{Na}$ [V] $1.5)$ and mediates the circadian variation in susceptibility to arrhythmia in humans, as a potential target. ${ }^{17}$ Interestingly, as mentioned, patients with LQT3 due to SCN5 a mutations show a significant prolongation of QTc interval at night as well as increased adverse events during sleep.

\section{Vascular}

Circadian rhythmicity has been shown to affect the function of all major cell types in the vasculature. This section discusses vascular smooth muscle cells and endothelial cells.

\section{Vascular smooth muscle cells}

Under the dual regulation of neurohumoral input and the endothelial/nitric oxide system, vascular smooth muscle cells are critical in fine-tuning vascular resistance. Vascular smooth muscle cells also possess an intrinsic biological clock. Serum shock, angiotensin II, and retinoic acid have all been shown to synchronize the oscillation of clock gene expression. ${ }^{102,103}$ Chalmers et al demonstrated synchronized rhythmic expression of core clock genes and clock-controlled genes, such as tissue inhibitor of metalloproteinase 1 and 3 (Timp1 and Timp3, respectively), collagen $3 a 1$ (Col3a), transgelin 1 (Sm22 $\alpha$ ) and calponin 1 (Cnn1) in a mouse smooth muscle cell line (Movas-1) using norepinephrine or forskolin as 
zeitgebers. ${ }^{104}$ Circadian expression of core clock genes (PER2 and BMAL1) is attenuated in senescent human smooth muscle cells. Ectopic expression of TERT (telomerase) in senescent cells or treatment with forskolin, a PKA activator, restores circadian rhythmicity and serum responsiveness via activation of cyclic adenosine monophosphate response element-binding (CREB) protein. ${ }^{105}$ In addition, Saito et al showed that Rho-associated kinase 2 (ROCK2) plays a pivotal role in generating the intrinsic circadian rhythm of vascular contractility by receiving a cue from ROR- $\alpha .{ }^{106}$

\section{Vascular endothelial cells}

Endothelial function measured by brachial artery flowmediated endothelium-dependent vasodilation is reduced in the early morning $(6 \mathrm{am})$ in healthy individuals. ${ }^{107}$ In vitro studies have confirmed the function of the peripheral clock in vascular endothelial cells and identified important clock-controlled genes, including thrombomodulin, which codes for a membrane protein with anticoagulation activity. ${ }^{108}$ Aortic rings from mice with the Per2 mutation show impaired endothelium-dependent relaxation in response to acetylcholine, associated with decreased production of nitric oxide and vasodilatory prostaglandins and increased production of cyclooxygenase-1, which is independent of BP or dyslipidemia. ${ }^{12}$ Similar findings in Bmall knockout mice and Clock mutant mice have been reported, and thought to be due to attenuated AKT signaling and reduced production of nitric oxide, at least in Bmall knockout arteries. ${ }^{109}$

In endothelial cells, the tissue plasminogen activator inhibitor 1 (PAI-1) promoter is under the direct regulation of cycle-like factor (CLIF)/CLOCK, BMAL1/CLOCK, and BMAL2/CLOCK heterodimers, ${ }^{110,111}$ and is inhibited by CRY and PER proteins. Westgate et al observed a diurnal variation of thrombosis in response to photochemical injury. ${ }^{19}$ In addition, this diurnal variation was abolished in Clock mutant mice, which showed a significantly longer time to thrombotic vascular occlusion, whereas global and endothelial deletion of Bmall was associated with a loss of circadian oscillation and a shortened time to thrombotic vascular occlusion. ${ }^{19}$

Endothelial progenitor cells have an important function in endothelial repair and postnatal neovascularization. ${ }^{112}$ A reduced number of circulating endothelial progenitor cells has been associated with increased cardiovascular risk. ${ }^{113}$ Landmark studies by Méndez-Ferrer et al reported that circulating hematopoietic stem cells and their progenitors (including endothelial progenitor cells) show robust circadian fluctuations, peaking 5 hours after the initiation of light and reaching a nadir 5 hours after darkness. The cyclic release of hematopoietic stem cells is under the regulation of photic stimuli via core clock genes, the sympathetic nervous system, and stromal derivative factor-1 (CXCL12). ${ }^{114}$ Normal individuals showed the highest number of circulating endothelial progenitor cells in the evening $(10 \mathrm{pm}){ }^{115} \mathrm{On}$ the other hand, studies in diabetic patients and in a diabetic rat model showed decreased release of endothelial progenitor cells, which was attributed to bone marrow neuropathy and decreased vascular reparative capacity. ${ }^{93}$ Endothelial progenitor cells from Per2 mutant mice showed reduced mobilization and response to vascular endothelial growth factor stimulation. Interestingly, endothelial progenitor cells from Per2 mutant mice and Bmall knockout mice showed an opposite effect on AKT activation, although both showed impaired endothelial function. ${ }^{116}$ This may represent their opposing relationship in the core clock transcription regulatory loop and anti-phasic expression. It is conceivable that the Yin of increased injury due to increased shear stress and vascular tone and the Yang of concomitantly lowered repair mechanisms due to reduced endothelial progenitor cell number and function contribute to the excess adverse cardiovascular events in the early morning.

\section{Extrinsic factors} Neurohumoral

A host of neurohumoral factors acting on the cardiovascular system demonstrate circadian rhythmicity, and have an important role in entraining the peripheral cardiovascular system to the central clock. Sympathetic activity dominates during the day and peaks in the morning, whereas parasympathetic activity peaks at night. The renin-angiotensinaldosterone system, ${ }^{117,118}$ vasoactive intestinal peptide, ${ }^{119}$ and atrial natriuretic peptide ${ }^{120}$ have all been shown to have diurnal variation in humans. Interestingly, secretion of cortisol, renin, and aldosterone show morning surges independent of activity; ${ }^{121,122}$ however, other processes, such as surges of catecholamines, are attenuated if the individual remains in bed in the morning. ${ }^{123,124}$

Neurohumoral factors such as norepinephrine, epinephrine, and angiotensin II, when added to aortic smooth muscle cells in vitro, can serve as a zeitgeber as predicted and synchronize clock gene oscillation. However, oscillation of clock genes was preserved ex vivo in aortic, heart, and liver tissues harvested from dopamine beta-hydroxylase knockout mice (Dbh-/-), which could not synthesize either norepinephrine or epinephrine and was chronically treated with both propranolol and terazosin, thereby excluding compensation by 
dopamine. ${ }^{125}$ Thus, although sympathetic signaling affects the peripheral cardiovascular diurnal rhythm, circadian rhythmicity is preserved even without any adrenergic input.

\section{Hematologic}

Macrophages

Chronic systemic inflammation and macrophage infiltration is closely associated with an increased risk of cardiovascular events, and is a dynamic area of research. In mice, the spleen, lymph nodes, and peritoneal macrophages all contain a peripheral clock and more than $8 \%$ of the macrophage transcriptome oscillates in a circadian fashion, including many important regulators for recognition of pathogens and secretion of cytokines. Lipopolysaccharide is a robust zeitgeber for macrophages in culture. The peripheral clock regulates inflammatory innate immune function, with isolated spleen cells stimulated with lipopolysaccharide at different circadian times displaying circadian rhythms in secretion of tumor necrosis factor-alpha and interleukin-6. ${ }^{126}$ Rev-erb $\alpha$ has been shown to regulate the expression of important genes involved in innate immunity, including IL6, IL19, CXCL6, CXCL1, and CCL2. ${ }^{127}$ Sato et al recently demonstrated that Rev-erb $\alpha$ directly suppresses CCL2 expression via a RORE element in the promoter and regulates infiltration of inflammatory macrophages. ${ }^{128}$ An elegant study by Cheng et al, using an arterial isograft transplant mouse model, demonstrated that wild-type grafts when anastomosed to either wildtype mice or mice with disrupted circadian clocks exhibit no pathology, whilst aortic grafts from Bmall knockout or Per2,3 double-knockout mice transplanted into wild-type mice led to development of robust arteriosclerotic disease, with upregulation of T-cell receptors, macrophages, and infiltrating cells in the vascular grafts, that was independent of hemodynamics and B-cell-mediated or T-cell-mediated immunity. ${ }^{18}$ This clearly demonstrates the crucial role of the peripheral clock in maintaining vascular health independent of the central clock.

\section{Other hematologic factors}

Both the number of circulating platelets and platelet aggregation show circadian variation. ${ }^{129,130}$ The hypercoagulability noted in the early morning is also associated with a peak in tissue factor pathway inhibitor and activated factor VII levels. ${ }^{131,132}$ Further, the number of vascular cell adhesion molecule-1-positive microparticles released from the endothelium in human plasma was reported to show a peak at 9 am, and was associated with increased coagulability through the tissue factor pathway. ${ }^{133}$ Further, levels of both prothrombin fragment (a marker for intravascular thrombin generation) and the plasmin-plasmin inhibitor complex (representing the degree of intravascular plasmin generation) were found to peak at 8 am. ${ }^{132}$ However, variations in platelet reactivity, fibrinogen, alpha 2 -antiplasmin, and plasminogen were abolished in supine individuals. ${ }^{124}$ Fibrinolytic activity, in contrast, peaks in the afternoon and troughs in the morning. ${ }^{129,134}$ Tissue plasminogen activator inhibitor 1 peaks at $4 \mathrm{am}^{135}$ and this diurnal variation persists in supine individuals. ${ }^{124}$ Interestingly, tissue-type plasminogen activator antigen also peaks in the morning; however, tissue-type plasminogen activator activity was found to be lower in the morning due to increased tissue plasminogen activator inhibitor 1 activity. ${ }^{136}$ Indeed, a high level of tissue plasminogen activator inhibitor 1, associated with low fibrinolytic activity, was found to be an independent risk factor for first acute MI in both men and women. ${ }^{137}$ The combination of increased platelet aggregability, ${ }^{138}$ blood viscosity, ${ }^{139}$ and thrombotic activity, ${ }^{19}$ as well as decreased fibrinolytic activity, ${ }^{135,140-142}$ would not only increase the size of an otherwise nonoccluding thrombus but would also increase its resistance to thrombolysis. ${ }^{141}$

An interesting study reported by Mou et al demonstrated the expression of tissue-type plasminogen activator and tissue plasminogen activator inhibitor 1 in the suprachiasmatic nucleus and their involvement in modulating photic phase shifts via activation of brain-derived neurotrophic factor ${ }^{143}$ in brain slices. It will be exciting to see follow-up in vivo studies in this regard.

\section{Therapeutic implications}

The circadian clock is altered or dampened in multiple human cardiovascular disorders and animal models, including hypertension, MI, and diabetes. Disturbed circadian rhythm is a risk factor for cardiovascular disease, as evidenced by studies in shift workers. In this section, we discuss therapeutic strategies that take advantage of our understanding of circadian regulation in the cardiovascular system.

\section{Chronotherapy}

The effectiveness and toxicity of many drugs varies according to time of administration because of the circadian rhythmicity of a number of biochemical, physiological, and behavioral processes. Chronotherapy became widely used in clinical practice when the alternate morning oral corticosteroid regimen was introduced in the early 1960s. ${ }^{144}$

As mentioned earlier, nondippers tend to have worse cardiovascular outcomes. The possibility of achieving "dipping” by 
pharmacologic intervention has been attempted in both animal and human studies with some success. Martino et al showed in mice that the benefit of captopril (a short-acting angiotensinconverting enzyme inhibitor) in cardiac remodeling after pressure overload is only observed when administered during sleep time but not during wake time despite the same level of BP control. ${ }^{98}$ Similarly, human studies showed that ramipril $5 \mathrm{mg}$ daily as monotherapy taken at bedtime was associated with significantly reduced BP during sleep (ie, improved “dipping") when compared with taking the drug on awakening. The proportion of patients with controlled ambulatory BP at 6 weeks increased from $43 \%$ to $65 \%(P=0.019)$ with treatment at bedtime. ${ }^{145}$ Further, in the Heart Outcomes Prevention Evaluation (HOPE) study, ramipril was administered at night, although without a direct control group, and the benefits seen were three times greater than predicted from previous studies based on BP reduction alone. ${ }^{146}$ The Ambulatory Blood Pressure Monitoring for Prediction of Cardiovascular Events (MAPEC) study directly compared morning versus nighttime doses and concluded that night dosing achieved overall better BP control in 2,156 individuals with a mean follow-up of 5.6 years, and this was associated with a lower risk of total cardiovascular disease events (relative risk 0.39, confidence interval $0.29-0.51, P<0.001){ }^{147,148}$

Chronotherapy as part of the personalized medicine that takes age, gender, and genetic background into consideration for an optimized regimen will be the goal of the foreseeable future. Drug delivery strategies incorporating knowledge of circadian rhythmicity will enable us to harness the benefit of chronotherapy without requiring meticulous compliance and adherence on the part of patients. Further, strategized therapies that aim to minimize or avoid the vulnerable window in the early morning for certain cardiovascular events, such as lethal MI and arrhythmia, will allow us to achieve chronoprevention.

\section{Resynchronization}

After a 12-hour light-dark shift, as experienced by human shift workers, central clock (suprachiasmatic nucleus)-mediated entrainment of BP and heart rate occurs in 1-2 days in humans. ${ }^{149,150}$ However, the entrainment of cardiac peripheral clock and clock-controlled genes takes at least 5 days to occur, ${ }^{91}$ thus creating a window of dyssynchrony. Therapies aimed at facilitating the transition of the peripheral clock will have implications for shift workers as well as frequent jet travelers.

Aging has been shown to attenuate circadian oscillation in vascular smooth muscle cells, ${ }^{105}$ although the methodology used cannot distinguish whether this is due to overall dampened oscillation or an inability to synchronize within the cell population. Pharmacologic and behavior modifications that reinforce the "ticking of the clock" may ameliorate the cardiovascular risk factors associated with aging. In addition to changes in lighting conditions, nonphotic stimuli such as physical activity and feeding schedule have been shown to play key roles in entrainment of the peripheral clock. ${ }^{85,151,152}$ A small pilot study by Scheer et al showed that daily oral melatonin for 3 weeks reduced BP during sleep, with improved "dipping”. Although sleep was also improved, a direct correlation between improved sleep and decreased BP was not observed, suggesting that the beneficial effect on BP is independent of the improvement in sleep. ${ }^{153}$ More human studies are required to fully evaluate the potential of resynchronizing therapy.

\section{Resetting the "clock"}

A recent advance in the field has been the ability to directly manipulate the clock machinery. Two high throughput screens identified small molecules that inhibit the function of $\mathrm{CKI} \alpha / \delta$ and $\mathrm{CKI} / \delta$, thus preventing degradation of PER2 and significantly lengthening the circadian period in human and mouse cell lines as well as living zebra fish in one study. ${ }^{154,155}$ Chen et al reported additional molecules that affect the period length and, interestingly, amplitude "damper" and "enhancer", which further expand our toolbox for manipulating the clock. ${ }^{156}$ Of interest is a report by Solt et al that administration of a synthetic REV-ERB ligand in mice alters circadian behavior and the circadian pattern of gene expression in the hypothalamus as well as in peripheral tissues. Mice with diet-induced obesity treated with this ligand showed decreased obesity and a markedly improved metabolic profile with regard to dyslipidemia and hyperglycemia. ${ }^{157}$ These results suggest that directly manipulating the core clock machinery may be a new therapeutic opportunity in the treatment of cardiometabolic disease.

\section{Conclusion}

Our lives are intimately linked to the solar cycle. The cardiovascular system has evolved an intricate circadian rhythm that oscillates intrinsically and can be entrained to the environment by zeitgebers, such as activity, temperature, and feeding. Our knowledge of how peripheral tissue clocks coordinate with the central suprachiasmatic nucleus clock to regulate cardiovascular physiology has greatly advanced in recent years, from the simple observation of diurnal fluctuation of physiologic parameters, to the molecular mechanisms of clock and their regulation on tissue-specific clock output 
genes, to chemical tools for potential intervention in the clock itself. However, our insight into the molecular basis of circadian timing in a tissue-specific fashion is still limited and will continue to be a proliferating field of research in the immediate future. Discovering local physiologic and pharmacologic zeitgebers will not only shed light on circadian biology but also provide opportunities for specific intervention. Non-transcriptional control of the clock machinery is a brand new chapter in circadian biology, and on further exploration, may offer quicker and more local adaptation of the peripheral clock. Our ability to resynchronize or directly "reset" the clock is rapidly expanding, and holds promise for development of future therapeutic tools.

\section{Acknowledgment}

This work was supported by a National Institutes of Health grant to MKJ (HL112486) and an American Heart Association Established Investigator Award to MKJ (3EIA14370009).

\section{Disclosure}

The authors report no conflicts of interest in this work.

\section{References}

1. Chronic Disease Prevention and Health Promotion [homepage on the Internet]. Heart Disease and Stroke Prevention. Addressing the Nation's Leading Killers: At A Glance 2011. Atlanta, GA: Centers for Disease Control and Prevention. Available from: http://www.cdc.gov/ chronicdisease/resources/publications/aag/dhdsp.htm. Accessed March 12, 2014.

2. Millar-Craig MW, Bishop CN, Raftery EB. Circadian variation of blood pressure. Lancet. 1978;1:795-797.

3. Dilaveris PE, Farbom P, Batchvarov V, Ghuran A, Malik M. Circadian behavior of P-wave duration, $\mathrm{P}$-wave area, and PR interval in healthy subjects. Ann Noninvasive Electrocardiol. 2001;6:92-97.

4. Molnar J, Zhang F, Weiss J, Ehlert FA, Rosenthal JE. Diurnal pattern of $\mathrm{QT}_{\mathrm{C}}$ interval: how long is prolonged? Possible relation to circadian triggers of cardiovascular events. J Am Coll Cardiol. 1996;27: $76-83$.

5. Cohen MC, Rohtla KM, Lavery CE, Muller JE, Mittleman MA. Metaanalysis of the morning excess of acute myocardial infarction and sudden cardiac death. Am J Cardiol. 1997;79:1512-1516.

6. Muller JE, Stone PH, Turi ZG, et al. Circadian variation in the frequency of onset of acute myocardial infarction. $N$ Engl J Med. 1985;313: $1315-1322$.

7. Sacco S, Toni D, Bignamini AA, et al. Acute stroke admission and diagnostic procedures according to the hour and day of onset: the SIRIO collaborative data. Eur Neurol. 2009;61:100-106.

8. Mehta RH, Manfredini R, Hassan F, et al. Chronobiological patterns of acute aortic dissection. Circulation. 2002;106:1110-1115.

9. Knutsson A, Akerstedt T, Jonsson BG, Orth-Gomer K. Increased risk of ischaemic heart disease in shift workers. Lancet. 1986;2:89-92.

10. Viitasalo K, Lindstrom J, Hemio K, et al. Occupational health care identifies risk for type 2 diabetes and cardiovascular disease. Prim Care Diabetes. 2012;6:95-102.

11. Janssen BJ, Tyssen CM, Duindam H, Rietveld WJ. Suprachiasmatic lesions eliminate 24-h blood pressure variability in rats. Physiol Behav. 1994;55:307-311.
12. Viswambharan H, Carvas JM, Antic V, et al. Mutation of the circadian clock gene per2 alters vascular endothelial function. Circulation. 2007;115:2188-2195.

13. Durgan DJ, Pulinilkunnil T, Villegas-Montoya C, et al. Short communication: Ischemia/reperfusion tolerance is time-of-daydependent: mediation by the cardiomyocyte circadian clock. Circ Res. 2010;106:546-550.

14. Durgan DJ, Tsai JY, Grenett MH, et al. Evidence suggesting that the cardiomyocyte circadian clock modulates responsiveness of the heart to hypertrophic stimuli in mice. Chronobiol Int. 2011;28:187-203.

15. Virag JA, Dries JL, Easton PR, et al. Attenuation of myocardial injury in mice with functional deletion of the circadian rhythm gene mper2. Am J Physiol Heart Circ Physiol. 2010;298:H1088-H1095.

16. Virag JA, Anderson EJ, Kent SD, et al. Cardioprotection via preserved mitochondrial structure and function in the mper2-mutant mouse myocardium. Am J Physiol Heart Circ Physiol. 2013;305:H477-H483.

17. Schroder EA, Lefta M, Zhang X, et al. The cardiomyocyte molecular clock, regulation of scn5a, and arrhythmia susceptibility. Am J Physiol Cell Physiol. 2013;304:C954-C965.

18. Cheng B, Anea CB, Yao L, et al. Tissue-intrinsic dysfunction of circadian clock confers transplant arteriosclerosis. Proc Natl Acad Sci U S A. 2011;108:17147-17152.

19. Westgate EJ, Cheng Y, Reilly DF, et al. Genetic components of the circadian clock regulate thrombogenesis in vivo. Circulation. 2008;117: 2087-2095.

20. Clark LA, Denby L, Pregibon D, et al. A quantitative analysis of the effects of activity and time of day on the diurnal variations of blood pressure. J Chronic Dis. 1987;40:671-681.

21. Fava C, Burri P, Almgren P, et al. Dipping and variability of blood pressure and heart rate at night are heritable traits. Am J Hypertens. 2005; 18:1402-1407.

22. O’Brien E, Sheridan J, O’Malley K. Dippers and non-dippers. Lancet. 1988;2:397.

23. Higashi Y, Nakagawa K, Kimura M, et al. Circadian variation of blood pressure and endothelial function in patients with essential hypertension: a comparison of dippers and non-dippers. $J$ Am Coll Cardiol. 2002;40:2039-2043.

24. Suwazono Y, Dochi M, Sakata K, et al. Shift work is a risk factor for increased blood pressure in Japanese men: a 14-year historical cohort study. Hypertension. 2008;52:581-586.

25. Lee KW, Blann AD, Lip GY. High pulse pressure and nondipping circadian blood pressure in patients with coronary artery disease: relationship to thrombogenesis and endothelial damage/dysfunction. Am J Hypertens. 2005;18:104-115.

26. Wilhelmsen L, Svardsudd K, Korsan-Bengtsen K, Larsson B, Welin L, Tibblin G. Fibrinogen as a risk factor for stroke and myocardial infarction. N Engl J Med. 1984;311:501-505.

27. Hermida RC, Calvo C, Ayala DE, et al. Seasonal variation of fibrinogen in dipper and nondipper hypertensive patients. Circulation. 2003;108:1101-1106.

28. Shimada K, Kario K. Altered circadian rhythm of blood pressure and cerebrovascular damage. Blood Press Monit. 1997;2:333-338.

29. Bianchi S, Bigazzi R, Baldari G, Sgherri G, Campese VM. Diurnal variations of blood pressure and microalbuminuria in essential hypertension. Am J Hypertens. 1994;7:23-29.

30. Timio M, Venanzi S, Lolli S, et al. "Non-dipper" hypertensive patients and progressive renal insufficiency: a 3-year longitudinal study. Clin Nephrol. 1995;43:382-387.

31. Davidson MB, Hix JK, Vidt DG, Brotman DJ. Association of impaired diurnal blood pressure variation with a subsequent decline in glomerular filtration rate. Arch Intern Med. 2006;166:846-852.

32. Verdecchia P, Porcellati C, Schillaci G, et al. Ambulatory blood pressure. An independent predictor of prognosis in essential hypertension. Hypertension. 1994;24:793-801.

33. Ohkubo T, Hozawa A, Yamaguchi J, et al. Prognostic significance of the nocturnal decline in blood pressure in individuals with and without high 24-h blood pressure: The Ohasama study. J Hypertens. 2002;20: 2183-2189. 
34. Kario K, Pickering TG, Matsuo T, Hoshide S, Schwartz JE, Shimada K. Stroke prognosis and abnormal nocturnal blood pressure falls in older hypertensives. Hypertension. 2001;38:852-857.

35. Zakopoulos NA, Tsivgoulis G, Barlas G, et al. Time rate of blood pressure variation is associated with increased common carotid artery intima-media thickness. Hypertension. 2005;45:505-512.

36. Marfella R, Siniscalchi M, Portoghese M, et al. Morning blood pressure surge as a destabilizing factor of atherosclerotic plaque: role of ubiquitin-proteasome activity. Hypertension. 2007;49:784-791.

37. Kario K, Pickering TG, Umeda Y, et al. Morning surge in blood pressure as a predictor of silent and clinical cerebrovascular disease in elderly hypertensives: a prospective study. Circulation. 2003;107:1401-1406.

38. Li Y, Thijs L, Hansen TW, et al. Prognostic value of the morning blood pressure surge in 5645 subjects from 8 populations. Hypertension. 2010;55:1040-1048.

39. Verdecchia P, Angeli F, Mazzotta G, et al. Day-night dip and early-morning surge in blood pressure in hypertension: prognostic implications. Hypertension. 2012;60:34-42.

40. Portaluppi F, Hermida RC. Circadian rhythms in cardiac arrhythmias and opportunities for their chronotherapy. Adv Drug Deliv Rev. 2007;59: 940-951.

41. Chugh SS, Jui J, Gunson K, et al. Current burden of sudden cardiac death: multiple source surveillance versus retrospective death certificate-based review in a large US community. J Am Coll Cardiol. 2004;44:1268-1275.

42. Behrens S, Galecka M, Bruggemann T, et al. Circadian variation of sustained ventricular tachyarrhythmias terminated by appropriate shocks in patients with an implantable cardioverter defibrillator. Am Heart $J$. 1995;130:79-84.

43. Kozak M, Krivan L, Semrad B. Circadian variations in the occurrence of ventricular tachyarrhythmias in patients with implantable cardioverter defibrillators. Pacing Clin Electrophysiol. 2003;26:731-735.

44. Englund A, Behrens S, Wegscheider K, Rowland E. Circadian variation of malignant ventricular arrhythmias in patients with ischemic and nonischemic heart disease after cardioverter defibrillator implantation. European 7219 JEWEL investigators. J Am Coll Cardiol. 1999;34: 1560-1568.

45. Gami AS, Howard DE, Olson EJ, Somers VK. Day-night pattern of sudden death in obstructive sleep apnea. $N$ Engl J Med. 2005;352: 1206-1214.

46. Guilleminault C, Connolly SJ, Winkle RA. Cardiac arrhythmia and conduction disturbances during sleep in 400 patients with sleep apnea syndrome. Am J Cardiol. 1983;52:490-494.

47. Svorc P, Benacka R, Petrasova D, Bracokova I, Kujanik S. Effect of systemic hypoxia and reoxygenation on electrical stability of the rat myocardium: chronophysiological study. Physiol Res. 2005;54: 319-325.

48. Stramba-Badiale M, Priori SG, Napolitano C, et al. Gene-specific differences in the circadian variation of ventricular repolarization in the long QT syndrome: a key to sudden death during sleep? Ital Heart J. 2000;1:323-328.

49. Mogabgab O, Wiviott SD, Antman EM, et al. Relation between time of symptom onset of st-segment elevation myocardial infarction and patient baseline characteristics: from the National Cardiovascular Data Registry. Clin Cardiol. 2013;36:222-227.

50. Cannon $\mathrm{CP}, \mathrm{McCabe} \mathrm{CH}$, Stone $\mathrm{PH}$, et al. Circadian variation in the onset of unstable angina and non-Q-wave acute myocardial infarction (the TIMI III Registry and TIMI IIIB). Am J Cardiol. 1997;79: 253-258.

51. Mahmoud KD, Lennon RJ, Ting HH, Rihal CS, Holmes DR Jr. Circadian variation in coronary stent thrombosis. JACC Cardiovasc Interv. 2011;4:183-190.

52. Ridker PM, Manson JE, Buring JE, Muller JE, Hennekens CH. Circadian variation of acute myocardial infarction and the effect of low-dose aspirin in a randomized trial of physicians. Circulation. 1990;82: 897-902.
53. Reiter R, Swingen C, Moore L, Henry TD, Traverse JH. Circadian dependence of infarct size and left ventricular function after st elevation myocardial infarction. Circ Res. 2012;110:105-110.

54. Suarez-Barrientos A, Lopez-Romero P, Vivas D, et al. Circadian variations of infarct size in acute myocardial infarction. Heart. 2011;97: 970-976.

55. Fournier S, Eeckhout E, Mangiacapra F, et al. Circadian variations of ischemic burden among patients with myocardial infarction undergoing primary percutaneous coronary intervention. Am Heart J. 2012;163: 208-213.

56. Ammirati E, Cristell N, Cianflone D, et al. Questing for circadian dependence in ST-segment-elevation acute myocardial infarction: a multicentric and multiethnic study. Circ Res. 2013;112:e110-e114.

57. Tsementzis SA, Gill JS, Hitchcock ER, Gill SK, Beevers DG. Diurnal variation of and activity during the onset of stroke. Neurosurgery. 1985; 17:901-904.

58. Johansson BB, Norrving B, Widner H, Wu JY, Halberg F. Stroke incidence: circadian and circaseptan (about weekly) variations in onset. Prog Clin Biol Res. 1990;341A:427-436.

59. Ricci S, Celani MG, Vitali R, La Rosa F, Righetti E, Duca E. Diurnal and seasonal variations in the occurrence of stroke: a community-based study. Neuroepidemiology. 1992;11:59-64.

60. Sloan MA, Price TR, Foulkes MA, et al. Circadian rhythmicity of stroke onset. Intracerebral and subarachnoid hemorrhage. Stroke. 1992;23:1420-1426.

61. Gallerani M, Trappella G, Manfredini R, Pasin M, Napolitano M, Migliore A. Acute intracerebral haemorrhage: circadian and circannual patterns of onset. Acta Neurol Scand. 1994;89:280-286.

62. Gallerani M, Portaluppi F, Grandi E, Manfredini R. Circadian rhythmicity in the occurrence of spontaneous acute dissection and rupture of thoracic aorta. J Thorac Cardiovasc Surg. 1997;113:603-604.

63. Manfredini R, Portaluppi F, Zamboni P, Salmi R, Gallerani M. Circadian variation in spontaneous rupture of abdominal aorta. Lancet. 1999;353:643-644.

64. Sumiyoshi M, Kojima S, Arima M, et al. Circadian, weekly, and seasonal variation at the onset of acute aortic dissection. Am J Cardiol. 2002;89:619-623.

65. Kojima S, Sumiyoshi M, Nakata Y, Daida H. Triggers and circadian distribution of the onset of acute aortic dissection. Circ J. 2002;66: 232-235.

66. Lasica RM, Perunicic J, Mrdovic I, et al. Temporal variations at the onset of spontaneous acute aortic dissection. Int Heart J. 2006;47: 585-595.

67. Killeen S, Neary P, O'Sullivan M, Redmond HP, Fulton G. Daily diurnal variation in admissions for ruptured abdominal aortic aneurysms. World J Surg. 2007;31:1869-1871.

68. Zarich S, Waxman S, Freeman RT, Mittleman M, Hegarty P, Nesto RW. Effect of autonomic nervous system dysfunction on the circadian pattern of myocardial ischemia in diabetes mellitus. J Am Coll Cardiol. 1994;24:956-962.

69. Fava S, Azzopardi J, Muscat HA, Fenech FF. Absence of circadian variation in the onset of acute myocardial infarction in diabetic subjects. $\mathrm{Br}$ Heart J. 1995;74:370-372.

70. Rana JS, Mukamal KJ, Morgan JP, Muller JE, Mittleman MA. Circadian variation in the onset of myocardial infarction: effect of duration of diabetes. Diabetes. 2003;52:1464-1468.

71. Ewing DJ, Borsey DQ, Travis P, Bellavere F, Neilson JM, Clarke BF. Abnormalities of ambulatory 24-hour heart rate in diabetes mellitus. Diabetes. 1983;32:101-105.

72. Taniguchi H, Inui M, Fujii M, et al. Cardiac beat-to-beat variation as an indicator of neuropathy and the frequency of its abnormality in diabetes mellitus. Tohoku J Exp Med. 1983;141 Suppl:471-478.

73. Ikeda T, Matsubara T, Sato Y, Sakamoto N. Circadian blood pressure variation in diabetic patients with autonomic neuropathy. J Hypertens. 1993;11:581-587.

74. Gilbert R, Phillips P, Clarke C, Jerums G. Day-night blood pressure variation in normotensive, normoalbuminuric type I diabetic subjects. Dippers and non-dippers. Diabetes Care. 1994;17:824-827. 
75. Nielsen FS, Rossing P, Bang LE, et al. On the mechanisms of blunted nocturnal decline in arterial blood pressure in NIDDM patients with diabetic nephropathy. Diabetes. 1995;44:783-789.

76. Pan A, Schernhammer ES, Sun Q, Hu FB. Rotating night shift work and risk of type 2 diabetes: two prospective cohort studies in women. PLoS Med. 2011;8:e1001141.

77. Kawachi I, Colditz GA, Stampfer MJ, et al. Prospective study of shift work and risk of coronary heart disease in women. Circulation. 1995;92: 3178-3182.

78. Kristensen TS. Cardiovascular diseases and the work environment. A critical review of the epidemiologic literature on nonchemical factors. Scand J Work Environ Health. 1989;15:165-179.

79. Boggild H, Knutsson A. Shift work, risk factors and cardiovascular disease. Scand J Work Environ Health. 1999;25:85-99.

80. Frost P, Kolstad HA, Bonde JP. Shift work and the risk of ischemic heart disease - a systematic review of the epidemiologic evidence. Scand J Work Environ Health. 2009;35:163-179.

81. Takahashi JS, Hong HK, Ko CH, McDearmon EL. The genetics of mammalian circadian order and disorder: implications for physiology and disease. Nat Rev Genet. 2008;9:764-775.

82. Edgar RS, Green EW, Zhao Y, et al. Peroxiredoxins are conserved markers of circadian rhythms. Nature. 2012;485:459-464.

83. O'Neill JS, van Ooijen G, Dixon LE, et al. Circadian rhythms persist without transcription in a eukaryote. Nature. 2011;469:554-558.

84. O'Neill JS, Reddy AB. Circadian clocks in human red blood cells. Nature. 2011;469:498-503.

85. Damiola F, Le Minh N, Preitner N, Kornmann B, Fleury-Olela F, Schibler U. Restricted feeding uncouples circadian oscillators in peripheral tissues from the central pacemaker in the suprachiasmatic nucleus. Genes Dev. 2000;14:2950-2961.

86. Storch KF, Lipan O, Leykin I, et al. Extensive and divergent circadian gene expression in liver and heart. Nature. 2002;417:78-83.

87. Akhtar RA, Reddy AB, Maywood ES, et al. Circadian cycling of the mouse liver transcriptome, as revealed by cdna microarray, is driven by the suprachiasmatic nucleus. Curr Biol. 2002;12:540-550.

88. Ueda HR, Chen W, Adachi A, et al. A transcription factor response element for gene expression during circadian night. Nature. 2002;418: 534-539.

89. Chatham JC, Young ME. Regulation of myocardial metabolism by the cardiomyocyte circadian clock. J Mol Cell Cardiol. 2013;55: 139-146.

90. Turek FW, Joshu C, Kohsaka A, et al. Obesity and metabolic syndrome in circadian clock mutant mice. Science. 2005;308:1043-1045.

91. Durgan DJ, Trexler NA, Egbejimi O, et al. The circadian clock within the cardiomyocyte is essential for responsiveness of the heart to fatty acids. J Biol Chem. 2006;281:24254-24269.

92. Collins HE, Rodrigo GC. Inotropic response of cardiac ventricular myocytes to beta-adrenergic stimulation with isoproterenol exhibits diurnal variation: involvement of nitric oxide. Circ Res. 2010;106: 1244-1252.

93. Busik JV, Tikhonenko M, Bhatwadekar A, et al. Diabetic retinopathy is associated with bone marrow neuropathy and a depressed peripheral clock. J Exp Med. 2009;206:2897-2906.

94. Qi L, Boateng SY. The circadian protein clock localizes to the sarcomeric Z-disk and is a sensor of myofilament cross-bridge activity in cardiac myocytes. Biochem Biophys Res Commun. 2006;351: 1054-1059.

95. Wang J, Dube DK, White J, Fan Y, Sanger JM, Sanger JW. Clock is not a component of z-bands. Cytoskeleton (Hoboken). 2012;69: 1021-1031.

96. Lefta M, Campbell KS, Feng HZ, Jin JP, Esser KA. Development of dilated cardiomyopathy in BMAL1-deficient mice. Am J Physiol Heart Circ Physiol. 2012;303:H475-H485.

97. Martino TA, Tata N, Belsham DD, et al. Disturbed diurnal rhythm alters gene expression and exacerbates cardiovascular disease with rescue by resynchronization. Hypertension. 2007;49:1104-1113.

98. Martino TA, Tata N, Simpson JA, et al. The primary benefits of angiotensin-converting enzyme inhibition on cardiac remodeling occur during sleep time in murine pressure overload hypertrophy. J Am Coll Cardiol. 2011;57:2020-2028.
99. Kung TA, Egbejimi O, Cui J, et al. Rapid attenuation of circadian clock gene oscillations in the rat heart following ischemia-reperfusion. $J \mathrm{Mol}$ Cell Cardiol. 2007;43:744-753.

100. Eckle T, Hartmann K, Bonney S, et al. Adora2b-elicited per2 stabilization promotes a hif-dependent metabolic switch crucial for myocardial adaptation to ischemia. Nat Med. 2012;18:774-782.

101. Jeyaraj D, Haldar SM, Wan X, et al. Circadian rhythms govern cardiac repolarization and arrhythmogenesis. Nature. 2012;483:96-99.

102. McNamara P, Seo SB, Rudic RD, SehgalA, Chakravarti D, FitzGerald GA. Regulation of clock and mop4 by nuclear hormone receptors in the vasculature: a humoral mechanism to reset a peripheral clock. Cell. 2001;105:877-889.

103. Nonaka H, Emoto N, Ikeda K, et al. Angiotensin ii induces circadian gene expression of clock genes in cultured vascular smooth muscle cells. Circulation. 2001;104:1746-1748.

104. Chalmers JA, Martino TA, Tata N, Ralph MR, Sole MJ, Belsham DD. Vascular circadian rhythms in a mouse vascular smooth muscle cell line (movas-1). Am J Physiol Regul Integr Comp Physiol. 2008;295: R1529-R1538.

105. Kunieda T, Minamino T, Katsuno T, et al. Cellular senescence impairs circadian expression of clock genes in vitro and in vivo. Circ Res. 2006;98:532-539.

106. Saito T, Hirano M, Ide T, et al. Pivotal role of rho-associated kinase 2 in generating the intrinsic circadian rhythm of vascular contractility. Circulation. 2013;127:104-114.

107. Otto ME, Svatikova A, Barretto RB, et al. Early morning attenuation of endothelial function in healthy humans. Circulation. 2004;109: 2507-2510.

108. Takeda N, Maemura K, Horie S, et al. Thrombomodulin is a clockcontrolled gene in vascular endothelial cells. J Biol Chem. 2007;282: 32561-32567.

109. Anea CB, Zhang M, Stepp DW, et al. Vascular disease in mice with a dysfunctional circadian clock. Circulation. 2009;119:1510-1517.

110. Maemura K, de la Monte SM, Chin MT, et al. Clif, a novel cycle-like factor, regulates the circadian oscillation of plasminogen activator inhibitor-1 gene expression. J Biol Chem. 2000;275:36847-36851.

111. Schoenhard JA, Smith LH, Painter CA, Eren M, Johnson CH, Vaughan DE. Regulation of the pai-1 promoter by circadian clock components: Differential activation by bmall and bmal2. J Mol Cell Cardiol. 2003;35:473-481.

112. Urbich C, Dimmeler S. Endothelial progenitor cells: characterization and role in vascular biology. Circ Res. 2004;95:343-353.

113. Shantsila E, Watson T, Lip GY. Endothelial progenitor cells in cardiovascular disorders. J Am Coll Cardiol. 2007;49:741-752.

114. Mendez-Ferrer S, Lucas D, Battista M, Frenette PS. Haematopoietic stem cell release is regulated by circadian oscillations. Nature. 2008;452:442-447.

115. Thomas HE, Redgrave R, Cunnington MS, Avery P, Keavney BD, Arthur HM. Circulating endothelial progenitor cells exhibit diurnal variation. Arterioscler Thromb Vasc Biol. 2008;28:e21-e22.

116. Wang CY, Wen MS, Wang HW, et al. Increased vascular senescence and impaired endothelial progenitor cell function mediated by mutation of circadian gene per2. Circulation. 2008;118:2166-2173.

117. Charloux A, Gronfier C, Lonsdorfer-WolfE, Piquard F, Brandenberger G. Aldosterone release during the sleep-wake cycle in humans. Am J Physiol. 1999;276:E43-E49.

118. Stern N, Sowers JR, McGinty D, et al. Circadian rhythm of plasma renin activity in older normal and essential hypertensive men: relation with inactive renin, aldosterone, cortisol and REM sleep. J Hypertens. 1986;4:543-550.

119. Kretschmannova K, Svobodova I, Balik A, Mazna P, Zemkova H. Circadian rhythmicity in AVP secretion and GABAergic synaptic transmission in the rat suprachiasmatic nucleus. Ann N Y Acad Sci. 2005;1048:103-115.

120. Watanabe T, Uchiyama Y. Quantitative analyses of atrial myoendocrine cells and plasma atrial natriuretic peptides (ANP) of the rat with special reference to the twenty-four-hour variations in secretory granules and plasma anp concentrations. Cell Tissue Res. 1988;254:133-137. 
121. Hurwitz S, Cohen RJ, Williams GH. Diurnal variation of aldosterone and plasma renin activity: timing relation to melatonin and cortisol and consistency after prolonged bed rest. J Appl Physiol. 2004;96: $1406-1414$

122. Weitzman ED, Fukushima D, Nogeire C, Roffwarg H, Gallagher TF, Hellman L. Twenty-four hour pattern of the episodic secretion of cortisol in normal subjects. J Clin Endocrinol Metab. 1971;33: 14-22.

123. Schofl C, Becker C, Prank K, von zur Muhlen A, Brabant G. Twentyfour-hour rhythms of plasma catecholamines and their relation to cardiovascular parameters in healthy young men. Eur J Endocrinol. 1997; 137:675-683.

124. Rosenfeld BA, Faraday N, Campbell D, Sakima N, Bell W. The effects of bedrest on circadian changes in hemostasis. Thromb Haemost. 1994;72:281-284.

125. Reilly DF, Curtis AM, Cheng Y, et al. Peripheral circadian clock rhythmicity is retained in the absence of adrenergic signaling. $J$ Clin Endocrinol Metab. 2008;28:121-126.

126. Keller M, Mazuch J, Abraham U, et al. A circadian clock in macrophages controls inflammatory immune responses. Proc Natl Acad Sci U S A. 2009;106:21407-21412.

127. Gibbs JE, Blaikley J, Beesley S, et al. The nuclear receptor rev-erbalpha mediates circadian regulation of innate immunity through selective regulation of inflammatory cytokines. Proc Natl Acad Sci U S A. 2012;109:582-587.

128. Sato S, Sakurai T, Ogasawara J, et al. A circadian clock gene, reverbalpha, modulates the inflammatory function of macrophages through the negative regulation of CCL2 expression. J Immunol. 2014;192:407-417.

129. Jovicic A, Ivanisevic V, Nikolajevic R. Circadian variations of platelet aggregability and fibrinolytic activity in patients with ischemic stroke. Thromb Res. 1991;64:487-491.

130. Undar L, Turkay C, Korkmaz L. Circadian variation in circulating platelet aggregates. Ann Med. 1989;21:429-433.

131. Pinotti M, Bertolucci C, Portaluppi F, et al. Daily and circadian rhythms of tissue factor pathway inhibitor and factor VII activity. Arterioscler Thromb Vasc Biol. 2005;25:646-649.

132. Kapiotis S, Jilma B, Quehenberger P, Ruzicka K, Handler S, Speiser W. Morning hypercoagulability and hypofibrinolysis. Diurnal variations in circulating activated factor vii, prothrombin fragment f1+2, and plasmin-plasmin inhibitor complex. Circulation. 1997;96: $19-21$.

133. Madden LA, Vince RV, Sandstrom ME, Taylor L, McNaughton L, Laden G. Microparticle-associated vascular adhesion molecule-1 and tissue factor follow a circadian rhythm in healthy human subjects. Thromb Haemost. 2008;99:909-915.

134. Rosing DR, Brakman P, Redwood DR, et al. Blood fibrinolytic activity in man. Diurnal variation and the response to varying intensities of exercise. Circ Res. 1970;27:171-184.

135. Bridges AB, McLaren M, Scott NA, Pringle TH, McNeill GP, Belch JJ. Circadian variation of tissue plasminogen activator and its inhibitor, von willebrand factor antigen, and prostacyclin stimulating factor in men with ischaemic heart disease. Br Heart J. 1993;69: $121-124$.

136. Angleton P, Chandler WL, Schmer G. Diurnal variation of tissue-type plasminogen activator and its rapid inhibitor (PAI-1). Circulation. 1989;79:101-106.

137. Thogersen AM, Jansson JH, Boman K, et al. High plasminogen activator inhibitor and tissue plasminogen activator levels in plasma precede a first acute myocardial infarction in both men and women: evidence for the fibrinolytic system as an independent primary risk factor. Circulation. 1998;98:2241-2247.
138. Tofler GH, Brezinski D, Schafer AI, et al. Concurrent morning increase in platelet aggregability and the risk of myocardial infarction and sudden cardiac death. $N$ Engl J Med. 1987;316:1514-1518.

139. Ehrly AM, Jung G. Circadian rhythm of human blood viscosity. Biorheology. 1973;10:577-583.

140. Kurnik PB. Circadian variation in the efficacy of tissue-type plasminogen activator. Circulation. 1995;91:1341-1346.

141. Andreotti F, Davies GJ, Hackett DR, et al. Major circadian fluctuations in fibrinolytic factors and possible relevance to time of onset of myocardial infarction, sudden cardiac death and stroke. Am J Cardiol. 1988;62:635-637.

142. Huber K, Rosc D, Resch I, Schuster E, Glogar DH, Kaindl F, Binder BR. Circadian fluctuations of plasminogen activator inhibitor and tissue plasminogen activator levels in plasma of patients with unstable coronary artery disease and acute myocardial infarction. Thromb Haemost. 1988;60:372-376.

143. Mou X, Peterson CB, Prosser RA. Tissue-type plasminogen activatorplasmin-bdnf modulate glutamate-induced phase-shifts of the mouse suprachiasmatic circadian clock in vitro. Eur J Neurosci. 2009;30: 1451-1460.

144. Harter JG, Reddy WJ, Thorn GW. Studies on an intermittent corticosteroid dosage regimen. $N$ Engl J Med. 1963;269:591-596.

145. Hermida RC, Ayala DE. Chronotherapy with the angiotensinconverting enzyme inhibitor ramipril in essential hypertension: improved blood pressure control with bedtime dosing. Hypertension. 2009;54:40-46.

146. Sleight P, Yusuf S, Pogue J, Tsuyuki R, Diaz R, Probstfield J. Bloodpressure reduction and cardiovascular risk in hope study. Lancet. 2001;358:2130-2131.

147. Flack JM, Nasser SA. Benefits of once-daily therapies in the treatment of hypertension. Vasc Health Risk Manag. 2011;7:777-787.

148. Hermida RC, Ayala DE, Mojon A, Fernandez JR. Influence of circadian time of hypertension treatment on cardiovascular risk: results of the MAPEC study. Chronobiol Int. 2010;27:1629-1651.

149. Chau NP, Mallion JM, de Gaudemaris R, et al. Twenty-four-hour ambulatory blood pressure in shift workers. Circulation. 1989;80:341-347.

150. Sundberg S, Kohvakka A, Gordin A. Rapid reversal of circadian blood pressure rhythm in shift workers. J Hypertens. 1988;6:393-396.

151. Stokkan KA, Yamazaki S, Tei H, Sakaki Y, Menaker M. Entrainment of the circadian clock in the liver by feeding. Science. 2001;291: 490-493.

152. Buxton OM, Lee CW, L'Hermite-Baleriaux M, Turek FW, Van Cauter E. Exercise elicits phase shifts and acute alterations of melatonin that vary with circadian phase. Am J Physiol Regul Integr Comp Physiol. 2003;284:R714-R724.

153. Scheer FA, Van Montfrans GA, van Someren EJ, Mairuhu G, Buijs RM. Daily nighttime melatonin reduces blood pressure in male patients with essential hypertension. Hypertension. 2004;43:192-197.

154. Isojima Y, Nakajima M, Ukai H, et al. Ckiepsilon/delta-dependent phosphorylation is a temperature-insensitive, period-determining process in the mammalian circadian clock. Proc Natl Acad Sci USA. 2009;106:15744-15749.

155. Hirota T, Lee JW, Lewis WG, et al. High-throughput chemical screen identifies a novel potent modulator of cellular circadian rhythms and reveals CKIalpha as a clock regulatory kinase. PLoS Biol. 2010;8:e1000559.

156. Chen Z, Yoo SH, Park YS, et al. Identification of diverse modulators of central and peripheral circadian clocks by high-throughput chemical screening. Proc Natl Acad Sci U S A. 2012;109:101-106.

157. Solt LA, Wang Y, Banerjee S, et al. Regulation of circadian behaviour and metabolism by synthetic rev-erb agonists. Nature. 2012;485: $62-68$. 
ChronoPhysiology and Therapy

Dovepress

\section{Publish your work in this journal}

ChronoPhysiology and Therapy is an international, peer-reviewed, open access journal focusing on research into the cyclic variations and rhythmicity in physiological processes in the body and the research and development and optimal timing of administration of therapeutic targets to achieve improved outcomes and quality of life for the patient. The

manuscript management system is completely online and includes a very quick and fair peer-review system. Visit http://www.dovepress.com/ testimonials.php to read real quotes from published authors.

Submit your manuscript here: http://www.dovepress.com/chronophysiology-and-therapy-journal 